Article

\title{
Using RPL Model to Probe Trade-Offs among Negative Externalities of Controlling Invasive Species
}

\author{
Tzu-Ming Liu(®) \\ Graduate Institute of Marine Affairs, National Sun Yat-sen University, Kaohsiung 80424, Taiwan; \\ liutm@mail.nsysu.edu.tw or liutm.tw@gmail.com
}

Received: 16 September 2019; Accepted: 3 November 2019; Published: 5 November 2019

\begin{abstract}
This empirical study uses the choice experiment method to analyze the preferences of national park (NP) visitors regarding the negative externalities of NP measures to prevent and control invasive alien species (IAS). In addition, it estimates the visitor responses to the trade-offs between various negative externalities and the prices visitors are willing to pay. Based on these trade-offs and the willing-to-pay prices, NPs can plan IAS prevention that has the least impact on visitors. Adopting visitors to Taiwan's Shei-Pa National Park as the survey respondents, this paper uses a stratified random sampling method to select the survey time and applies systematic sampling to select respondents during the survey period. A total of 602 questionnaires and 2998 observations were obtained. The results reveal that visitors believe that the negative externalities of IAS have a significant impact on them. However, their preference for prevention and control outweighs their preference for no prevention and control measures. In terms of the negative externalities associated with IAS prevention and control, visitors award priority to avoidance of ecological disturbance and harm to visitor health, and are more likely to accept the reduction of recreational area.
\end{abstract}

Keywords: discrete choice experiments; random parameters logit (RPL) model; invasive species control; national park; two stage on-site sampling; negative externalities

\section{Introduction}

Invasive alien species (IAS) pose a serious threat to ecology, society, economy, and human health. Taking the United States (U.S.) as an example, losses caused by IAS are as high as 137 billion USD every year [1]. The impact of IAS on areas with critical ecological and terrestrial landscapes, as well as human activities (such as National Parks (NPs)), is even more acute. However, IAS prevention and control are not universally supported by the public [2,3]. Clarifying the various aspects of IAS prevention and control, including the shocks brought by IAS and the impact of prevention on the public, is vital to gaining public support and improving the effectiveness of prevention and control.

The ecological shocks caused by IAS include preying on other species, competing with other species for ecological resources, changing the characteristics of a habitat, genetic pollution, and so on. In the Archipelago NP of Finland, American mink (Mustela vison) has hunted four endangered species, including black guillemot (Cepphus grylle) [4], razorbill (Alca torda) [4], tufted duck (Aythya fuligula) [5], and velvet scoter (Melanitta fusca) [5]. In the U.S. Mojave National Preserve, Equus asinus has plundered the pasture, endangering the threatened desert tortoise (Gopherus agassizii (Cooper)) [6]. The structure and function of the ecosystem of the Donana NP Swamp in Spain have been dramatically altered by red swamp crayfish (Procambarus clarkia), which has affected the energy transmission path and reduced other species' food availability and refuge habitats [7]. The intensity of cultivation and soil nutrients in Uganda's Mgahinga Gorilla NP have been influenced by black wattle (Acacia mearnsii) [8]. In Malawi's Lake Malawi NP, the exotic cichlid fish (Cynotilapia afra) has hybridized with the local zebra mbuna 
(Metriaclima zebra) [9]. These shocks not only threaten endangered species, but also change habitat structure and landscape features and hinder biodiversity conservation.

In addition to the threats to biodiversity, risks caused by IAS to society, industry, and the environment should not be underestimated. Golden mussels (Limnoperna fortunei) damaged hydropower facilities [10] and jeopardized the operations of various industrial facilities, such as water purification plants, thermal power plants, cold storage plants, and oil refineries [11]. Water hyacinth (Eichhornia crassipes) can block rivers, irrigation channels, and reduce flow rate, making it difficult to obtain water. It might also increase flood risk and obstruct ship traffic [12]. Brown tree snakes (Boiga irregularis) damaged electric wire and caused power outages [13]. Yellow starthistle (Centaurea solsitialis L.) [3] can lower agricultural and animal husbandry outputs and decrease the environmental carrying capacity of wild animals and the quality of natural recreation. In the case of Idaho in the U.S., these costs were as high as 12.7 million USD [14].

Harm to human health is also one of the shocks of IAS. Ragweed (Ambrosia artemisiifolia) can release large amounts of pollen, causing complex rhinitis, asthma, skin allergy, hay fever, and other respiratory diseases and allergies [15]. The sap of giant hogweed (Heracleum mantegazzianum) is toxic. If the human body is stained with the sap, it will cause blisters, severe burns, and even blindness. After treatment, the skin is still photophobic, which means if it is exposed to the sun, it will relapse [16]. Parthenium weed (Parthenium hysterophorus) can cause eczematous contact dermatitis, asthma, and even severe allergic reactions [17].

The threats posed by the aforementioned IAS are from a wide variety of species. However, in fact, a single species can also lead to all these shocks. For example, the red imported fire ant (RIFA) (Solenopsis invicta) has threatened the existence of several rare and endangered species, such as Australian koalas (Phascolarctos cinereus), the Mary River turtle (Elusor macrurus), and Illidge's ant-blue butterfly (Acrodipsas illidgei), and might reduce the numbers of birds, mammals, reptiles, and amphibians in Australia by $45 \%, 38 \%, 69 \%$, and $95 \%$, respectively [18]. RIFA has extensive negative impacts on the production of agriculture, animal husbandry, forestry, and aquaculture. It also destroys power facilities and disrupts industrial production and transportation [19]. Moreover, RIFA stings may lead to anaphylactic shock, and there are many related reports of death due to RIFA in the U.S. [20].

The severity of these shocks caused by IAS around the world, if monetized, would be more obvious. In terms of the impacts of individual IAS, the total cost of a single species, the Formosan subterranean termite (Coptotermes formosanus), to the world is as high as 30.2 billion USD per year [21]. In terms of health shocks, the global health costs of invasive insects are as high as 6.9 billion USD [21]. In terms of agriculture production shock, the assessment by Paini, et al. [22] assessed the impacts of the known 1297 alien invasive species on agricultural production in 124 countries worldwide, and concluded that IAS lowered the annual agricultural outputs of China, the U.S., Brazil, India, and Japan by 117 billion USD, 70 billion USD, 33.7 billion USD, 33 billion USD, and 23 billion USD, respectively, equivalent to respective decreases of $4.59 \%, 0.58 \%, 3.54 \%, 3.92 \%$, and $0.52 \%$ of their GDP. In terms of the costs to energy, water conservancy, and transportation facilities, the United Kingdom has seen approximately 0.4 billion USD of losses every year [23].

Because the impacts of IAS are deep and significant, many scholars are dedicated to exploring prevention strategies. For example, Chen [24] and Douglas and Tooker [25] studied pesticides; Allison and Redak [26] and Juanes [27] researched prevention and monitoring; Wylie and Janssen-May [18] focused on inspection and surveillance; Gomes, et al. [28] explored decontamination; Colleran and Goodall [29] studied manual labor and chain saws. Unfortunately, these IAS prevention and control measures have their own negative effects of different types and degrees. For example, the Antioch Dunes National Wildlife Refuge used chemicals to suppress IAS. However, during the process, the pupation rate of Lange's metalmark butterfly (Apodemia mormo langei), an internationally endangered species, declined by 24-36\% [30]. Exposure to chemicals has also caused human neuropathy and DNA damage [31] and increased the risks of cancer [32]. Chemicals used by traps might disrupt the ecosystem [33]; establishing monitoring systems could limit the scope of public activities; 
decontamination might lead to traffic jams and extended public travel time [34]; the use of manual labor and chain saws could jeopardize ecosystems and landscapes [35], as well as interfere with and restrict people's activities. The costs of the side effects from IAS prevention (i.e., negative externalities) decide the feasibility of controlling IAS [2]. However, in practice, it is difficult to evaluate the costs of such negative externalities [36].

Reducing the negative externalities associated with IAS prevention control facilitates the stipulation of a reasonable and feasible IAS prevention and control mechanism that takes ecological benefits into account and is recognized by society. One way to accomplish this is to first understand the negative externalities of IAS prevention and the trade-offs between these negative externalities [37]. Then, the trade-offs must be evaluated based on the preferences of stakeholders for these negative externalities [3]. Finally, prevention and control plans can be stipulated by synthesizing the public preferences and opinions and these trade-offs. Plans obtained through this process could reduce the conflicts and confrontation in the implementation of the measures [3,37]. However, the costs to the public of controlling the negative externalities of IAS and the trade-offs between these side effects remain unclear. The lack of such information might risk the loss of public support for the implementation of IAS prevention and control measures [38]. Addressing such deficiencies in the existing literature would add to the insights needed to formulate publicly acceptable IAS prevention policies and applications.

The public's willingness to pay for the externalities of IAS prevention and control measures could be used as costs of the negative externalities, as well as the public's trade-offs between various negative externalities. A single outcome could provide the two types of missing information mentioned in the above paragraph. There are two ways to measure willingness to pay, namely, revealed preference and stated preference. The revealed willingness to pay must be evaluated through real goods transactions. However, there is currently no market for evaluating IAS prevention and control measures. It is therefore impossible to measure willingness to pay in this area using revealed preference. Using questionnaires, the stated preference method solves the problem of a lack of actual market by creating one. Therefore, this approach could be used to assess the public's willingness to pay for IAS prevention and control measures. For example, Mwebaze, et al. [39], Adams, et al. [40], McIntosh, et al. [41], Rolfe and Windle [42], Bithas, et al. [43], and Chakir, et al. [44] all used this method to study the public's willingness to pay for the prevention or removal of IAS conservation policy. The stated preference approach used in the aforementioned literature could be further divided into the contingent valuation method and the choice experiment method. When using the contingent valuation method, the researcher only asks the respondents to make choices under one hypothetical condition, while the choice experiment asks respondents to choose under multiple hypothetical conditions. Boxall, et al. [45] compared the pros and cons of the contingent valuation and choice experiment methods and believed that the choice experiment method had several advantages. For example, the choice experiment method was able to present the respondents with multiple alternative conditions, so that the respondents could "select" and act in a way closer to their actual economic behaviors. Kanninen [46] also believed that the advantage of the choice experiment method over the contingent valuation method was that the former allowed respondents to choose between alternatives, so that they could better weigh the opportunity cost. In addition, the choice experiment method is able to obtain an individual's assessment of specific environmental attributes and avoid yea-saying bias [47].

Considering that there is no market for IAS prevention and control measures, and considering the advantages of the choice experiment method in analyzing diversified IAS prevention and control measures, various types of negative externalities associated with complicated IAS prevention and control measures, and all types of trade-offs between these negative externalities, we selected the choice experiment method to study the public preference regarding negative externalities of IAS prevention and control. The research location was Taiwan's Shei-Pa NP, and the research objects were visitors to the NP. The reason for choosing Shei-Pa NP as the research location is that NPs have the serious responsibility of protecting major ecosystems and landscapes, as well as satisfying people's needs for 
sightseeing and recreation. These diverse business objectives of NPs conflict regarding IAS issues, and therefore, IAS are regarded as the biggest challenge for NP management $[48,49]$. There is an urgent need to reconcile the prevention and control of IAS and the impacts of those measures on visitors. As a result, we conducted this research. The purposes of this research include (1) evaluating the public's willingness to pay for IAS prevention and control measures, (2) evaluating the public's willingness to pay for the various negative externalities of IAS prevention and control measures, (3) analyzing the public's trade-offs between various negative externalities of IAS prevention and control measures, and (4) assessing the impact of the negative externalities on the public support of IAS prevention and control measures.

\section{Negative Externalities of IAS Prevention and Control Measures}

IAS prevention and control methods can be approximately classified into "chemical agent methods", "prevention monitoring methods", "pollution removal methods", and "artificial removal methods". The "chemical agent method" involves the use of chemicals, such as insecticides or herbicides, to control IAS. Although this method is convenient and rapidly effective, it poses a serious threat to ecology and human health. Antioch Dunes National Wildlife Refuge used chemical agents to inhibit IAS, only to reduce the hatchability rate of the internationally endangered species Lange's metalmark butterfly to $24-36 \%$ [30]. Human exposure to chemicals causes neuropathy and DNA damage [31] and increases the risk of developing cancer [32]. Therefore, chemical control at an NP may threaten both conservation and visitor health.

The "prevention monitoring method" is a control measure that uses monitoring tools, such as pheromone-baited traps [26], light-based traps [50], and visual and acoustic sensors [27], for prevention or early detection. This measure can significantly reduce the risk of IAS invasion [51] or inhibit the speed of an IAS spreading [52]. The establishment of monitoring facilities in NPs incurs operational costs, thus adding financial pressure for park management. In addition, establishing areas for monitoring requires eliminating the possibility of visitor interference, thus reducing the available visiting area. The chemicals used by traps may also disturb park ecology [33], thus affecting the quality of recreational activities.

The "pollution removal method" uses disinfecting or cleaning equipment to remove IAS. This approach is primarily intended to prevent the unintentional spread of IAS carried on park equipment. An example is provided by the efforts to control didymo by Fiordland NP in New Zealand. Considering that the clothing and equipment of leisure anglers were the main contributors to didymo diffusion in the park [53], the New Zealand government requires visitors to be disinfected before entering the reserve to remove any attached didymo. Measures of this type delay visitors, or otherwise interfere with their itineraries. LeDoux and Martin [34] estimated the effect of the pollution removal method to be a delay of 15-20 min per person. Therefore, NP use of this method increases the time visitors must wait to enter the park. In addition, this method increases the visitor's chance of exposure to disinfectants.

"Manual removal" is a method whereby park staff remove the IAS directly by hand or using a tool. When manual removal is performed, NPs must close the area of the operation, causing certain recreational areas to be inaccessible to visitors, thus restricting their freedom of movement. This method may also endanger the ecology and the landscape [35].

The negative externalities of these measures for NP visitors can be summarized into four types: "Severe disturbance of the eco-environment by the prevention and control measures", "reduction in recreational or visiting areas due to the prevention and control measures", "possible negative impact of the prevention and control measures on visitor health", and "increased visitor waiting time caused by implementation of prevention and control measures". Next, we describe the content and meaning of each of the negative externalities (i.e., attributes in the choice experiment) and their levels.

(1) Severe disturbance to the eco-environment by the prevention and control measures (ecological impact) 
Abundance in biodiversity is an important factor for NPs in attracting visitors [54]. However, IAS prevention and control measures may have serious negative effects on biodiversity in the controlled area and reduce the utility of visitor sightseeing and recreational activity. Regarding disturbance to NP eco-environments by IAS prevention and control measures, we refer to studies on Booderee NP [55]. In one such study, Stark, Chen and Johnson [30] evaluated the impact of IAS prevention measure disturbance on the number of species populations to be 30\%. Based on Stark, Chen and Johnson [30] and the suggestion by Ryan, et al. [56] that the grade design of attributes should be $15 \%$ higher or lower than the reference value or the previous grade, the severity of ecological disturbance caused by IAS prevention and control measures is divided into the following five levels: $0,15,30,45$, and $60 \%$.

(2) Reduction in recreational or visiting areas due to the prevention and control measures (recreational area)

Measures to prevent and control IAS affect visitor recreational areas. For example, after spraying pesticide in a controlled area, the pesticide application area must be closed to prevent visitors from exposure to chemical agents. When the manual removal method is used, the affected areas are also closed to facilitate removal operations. To prevent interference, no visitor activities are allowed near monitoring facilities. However, partially closing park areas may cause resentment [57]. Therefore, limiting accessibility to park areas because of IAS prevention and control measures represents a negative externality. This attribute, expressed as a percentage of the reduction of the recreational or visiting area available to visitors, is set at $0,20,40,60$, and $80 \%$.

(3) Possible negative impact of the prevention and control measures on visitor health (health risks)

IAS prevention and control measures include chemical control. However, chemical agents can affect human health and cause disease [32]. Thus, using chemical methods for prevention and control in recreational areas represents a negative externality. At present, there are no specific empirical data that reflect the negative impact of chemical control of IAS on visitor health. Therefore, we assume the validity of the following levels: $0,30,60$, and $90 \%$.

(4) Increased visitor waiting time caused by implementation of prevention and control measures (waiting time)

Travel delays or time-consuming waits reduce tourism utility [58]. Therefore, when NPs implement IAS prevention measures, delayed entrance to an NP represents a negative externality. A study by LeDoux and Martin [34] found that the delay is approximately 15-20 min per person. Therefore, this study sets the levels of this attribute as follows: $0,20,40$, and $60 \mathrm{~min}$.

To assess the willing-to-pay price for each of the externalities of the IAS prevention and control measures, an attribute is established for "additional fees dedicated to prevention and control charged for entering attractions or parks".

(5) Additional fees dedicated to prevention and control charged for entering attractions or parks (charges for prevention and control)

The level of this fee is based on the research results of Adams, Bwenge, Lee, Larkin and Alavalapati [40]. Using 120 NTD as the reference value, the amount of each level is set as follows: 40, $80,120,160$, and 200 NTD.

The attributes and attribute levels are listed in Table A1 and an example of ASC choice set is listed in Table A2.

\section{Method}

\subsection{Questionnaire Design and Sampling Method}

The number of questionnaires for the choice experiment method depends on the number of scenarios, while the number of scenarios is impacted by the number of alternatives. In addition, the number of alternatives depends on the number of attributes and the number of levels of each attribute. When the number of attributes and the number of levels of each attribute cause the number of alternatives to be very large, it is impossible to design a reasonable and feasible number of scenarios. 
For example, if this study used a full factorial design, the number of questionnaire design alternatives would reach $5^{3} \times 4^{2}=2000$. If each scenario contains five alternatives, the number of scenarios is still as high as 400. Additionally, Rose and Bliemer [59] suggest that each scenario requires at least 25 observations. In this case, it is impossible to conduct research based on the number of alternatives, the number of scenarios, and the number of questionnaires generated by a full factorial design. Therefore, the number of scenarios is reduced by considering the statistical efficiency of scenario combinations.

Common methods used to reduce the number of alternatives include D-efficient design and orthogonal designs methods. The key is whether attributes or levels have a priori information. If a priori information is available, the D-efficient design can be used to generate alternatives. If the relevant a priori information cannot be obtained, the orthogonal design method can be used to generate alternatives [60]. A priori data can be quoted from the literature or obtained from actual questionnaire surveys. However, in this study, there were no available relevant studies on the attributes and levels used or sufficient resources to conduct surveys. Because of a lack of the a priori information required for D-efficient design, this study adopted the orthogonal design method to generate alternatives.

Using JMP 12 Pro Choice platform [61,62], we obtained 25 alternatives, which were divided into five groups, with each group representing a scenario. Additionally, to avoid a situation in which all five alternatives are likely to be accepted by respondents unwillingly or under pressure, such that the results are not consistent with the requirement, a "status quo" option was added to each scenario [63]. Each questionnaire contained all five scenarios, each of which had six alternatives. The order of alternatives was fixed within choice tasks, and thus, order effects may have occurred. Ladenburg and Olsen (2008) suggest that including examples of choice sets that are not intended for use in the analysis of preferences to reduce ordering effects. We followed Ladenburg and Olsen's suggestion and interviewees were offered the dummy choice set before receiving the real ones.

After the questionnaire was completed, a one-on-one cognitive interview was conducted to verify the questionnaire answers. This method provides an in-depth understanding of respondent opinions regarding the questionnaire contents and their cognitive responses in understanding and answering the questions. One of the skepticisms of choice experiment is the hypothetical nature and the potential bias in willingness to pay (WTP) estimates caused by the hypothetical bias. To avoid researchers and interviewees having a different understanding of the meaning of questionnaire items, interviewers were asked whether clarification was needed. A difference in understanding may result in misunderstanding or confusion on the respondent's part, thus affecting his or her responses [46]. The questionnaire was finalized after revision through this method and used for the local survey.

A problem often encountered in on-site surveys is that the sample is not representative Liu [64]. To overcome this problem, this study used two-stage sampling. A stratified random sampling method was used to sample the survey period, and during the survey period, systematic sampling was used to draw the sample. First, four survey months were randomly selected: March, July, August, and November. Subsequently, the distribution date of the questionnaire was randomly selected for each month. To determine the day of questionnaire distribution, a number between 0 and 9 was selected from a random number table to use as the date. On a date from the range, the visitor who passed the questionnaire distribution point in the order that matched the date number would be the first respondent for the day. Subsequently, taking three visitors as the sampling unit, we chose as the next respondent the third visitor to pass the questionnaire distribution point after the first respondent. By randomly selecting the survey time points and the initial respondent, a sample meeting the requirements of probability sampling was obtained. 


\subsection{Choice Experiment Methodology}

The choice experiment method uses the results of the respondents' choices in each scenario group to estimate the utility function of the respondents. Respondents choose the utility value of each scenario, which is expressed by the following equation:

$$
U_{i n}=V_{i n}+\varepsilon_{i n}, \forall i \in C_{n}
$$

where $U_{\text {in }}$ is the utility of respondent $n$ choosing alternative $i$. However, because the actual utility value of the respondent cannot be observed, $V_{\text {in }}$ is used to denote the observed utility of respondent $n$ choosing alternative $i . \varepsilon_{i n}$ is a random parameter that denotes the error term and is used as an unmeasurable item in the model. $C_{n}$ is the set of all the choices respondent $n$ can make.

The estimation method in Equation (1) depends on the distribution function of $\varepsilon_{i n}$. However, not all the distribution function settings meet the requirements of utility maximization. For the analysis results of the intermittent-choice experiment to be consistent with the decision-making behavior of maximizing the respondent's utility, the distribution function that satisfies the conditions of maximizing utility must be adopted. Because the random variables are independently and identically distributed (i.i.d.), type 1 extreme value distribution meets the conditions of utility maximization [65]. This study assumes that $\varepsilon_{\text {in }}$ is i.i.d. and type 1 extreme value distribution. Under this assumption, the probability that respondent $n$ chooses alternative $i$ is shown in Equation (2):

$$
P_{i n}=\frac{\exp \left(\mu V_{\text {in }}\right)}{\sum_{j \in C} \exp \left(\mu V_{j n}\right)}
$$

Estimation of Equation (2) still requires the function form between $V_{\text {in }}$ and the attributes. Assuming that $V_{\text {in }}$ is a linear function of the attributes, we express Equation (3) as follows:

$$
V_{\text {in }}=A S C_{i}+\beta_{1} X_{i 1} \ldots+\beta_{K} X_{i K}
$$

where $\beta_{K}$ represents the parameter of the attribute $K, X_{i K}$ represents the $K^{\text {th }}$ attribute of the respondent choosing alternative $i$, and the alternative-specific constant (ASC) is the indicator variable, which indicates whether the corresponding option is selected. Its estimated value is used to show the function that other attributes cannot show [66].

Under the previously noted assumption, the marginal rate of substitution between the two attributes, $k$ and $s$ for example, is shown in Equation (4):

$$
\mathrm{MRS}_{S K}=-\frac{\beta_{K}}{\beta_{S}}
$$

To calculate the trade-off relationship between other attributes and costs, let $s$ present the attribute of cost, the marginal willing-to-pay price equation can be used to obtain the respondent's willing-to-pay for $K$, as shown in Equation (5):

$$
\operatorname{MWTP}_{K}=-\frac{\beta_{K}}{\beta_{\text {cost }}}
$$

\subsection{Model Specification}

Different choice models arise from different distributions of the random part. Multinomial Logit (MNL) models, Nested Logit, Latent Class, Mixed Logit, Error Component, and Generalized Multinomial Logit are often used models [67]. Due to the advantage of the MNL model's simple and elegant closed-form mathematical structure, the choice probabilities are easy to be estimated and interpreted. Therefore, the MNL model is the most commonly used model [67]. However, the MNL model is not free of deficiencies. The MNL model is restricted and limited in three directions [68]. 
First, the MNL model assumes that the presence or absence of other "irrelevant" alternatives does not change the odds of preferring one class over another, which is known as the Independence from Irrelevant Alternatives (IIA) property, which can be rather unrealistic in many settings. Second, the MNL model cannot be used for panel data analyses, where several observations are considered for the same respondent and unobserved factors are dependent of each respondent over time. Third, the MNL model cannot incorporate differences in tastes that are not related to observed characteristics. Since, in our sample, there are several observations for each individual (panel data) which are not independent of each other, the assumptions of the MNL model are not valid in this case, as is shown by Liu and Tien [69].

The preference heterogeneity is also an important factor in determining how to estimate Equation (1). The presence of heterogeneous preferences for negative externalities may influence the establishment, as well as the operation of the IAS management. Demographic differences in preferences for the attributes in this study are observed. For example, preferences over health risk reductions can vary by age [70], education [71], gender [72], and income [71]. The MNL model is not capable of accounting for these heterogeneous preferences, and therefore is not suitable to be used in this study.

A random parameters logit (RPL) model [73] is appropriate when strong a priori assumptions, as mentioned in the previous paragraph, regarding the sources of heterogeneity exist. Respondents' heterogeneous preferences can be introduced into an RPL model, which allows variation in the preference parameters, $\beta$, across individuals and estimates $\beta$ as a function of observable characteristics of respondents. Furthermore, an RPL model can address heterogeneous preferences by interacting socioeconomic variables with attributes and with the alternative specific constant (ASC). Hence, an RPL model can reveal preference variation in terms of both unconditional heterogeneity and individual characteristics.

Given that out respondents faced five different choice scenarios, a panel of responses, and heterogeneous preferences exist among respondents, an RPL model is appropriate for this study. An RPL model is generalized from the MNL model. We can revise the form of utility in Equation (1) to include an additional term $\delta_{n} x_{n i k}$ that aims to capture random taste among individuals, and $\gamma_{m} z_{n m}$ that aims to capture correlation over alternatives and time/situation. The utility function of RPL model takes the form:

$$
U_{n i}=\alpha A S C+\sum_{k}\left[b x_{n i k}+\delta_{n} x_{n i k}\right]+\sum_{m}\left[\gamma_{m} z_{n m} \cdot \alpha A S C\right]+\varepsilon_{n i}
$$

where $\alpha$ is the constant term specified to take the value 1 when ASC is chosen and zero otherwise; $x_{n i k}$ is the value of attribute $k$ for alternative $i ; b$ represents the associate parameters of these attributes; $\gamma_{m}$ is the coefficient associated with the individual specific characteristics $z_{n m}$ (which interact with $\alpha$ given that they are constant over the alternatives); and $\varepsilon_{n i}$ is an unobserved random term that is independent of the other terms and independently and identically distributed with a Gumbel (type 1 extreme value) distribution. We can convert Equation (6) to a comparable form of the standard MNL model by substituting $\beta_{n}=b+\delta_{n}$, allowing the coefficients to vary randomly across respondents. Since the coefficient vector $\beta_{n}$ is not observed, we may assume that $\beta_{n}$ follows a distribution with density $f\left(\beta_{n}\right)$. Accordingly, the probability that a given individual $n$ choose alternative $i$ becomes:

$$
P_{n i}=\int \cdots \int \prod\left[\frac{e^{\beta_{n}^{\prime} x_{n i}}}{\sum_{j=1}^{J} e^{\beta_{n}^{\prime} x_{n j}}}\right] f(\beta) d \beta
$$

The intuition behind Equation (7) is that the probability of choosing alternative $i$ is weighted by the density $f(\beta)$.

Equation (7) has no closed-for solution but can be approximated by simulation. Distributions for the coefficients should be specified by the researcher and then calculate $P_{n i}$ for each draw. The simulated probability is an unbiased estimator of $P_{n i}$ [68]. 
For comparison, we also consider the standard multinomial logit model (MNL), as Tempesta, Vecchiato and Girardi [67] suggested.

The MNL tested is:

$$
\begin{aligned}
& U\left(X_{i}\right)=\beta_{A S C} \times A S C_{i}+\beta_{\text {Environment }} \times \text { Environment }_{i}+\beta_{\text {Recreation }} \times \text { Recreation }_{i} \\
& +\beta_{\text {Healthe }} \times \text { Health }_{i}+\beta_{\text {Time }} \times \text { Time }_{i}+\beta_{\text {Fee }} \times \text { Fee }_{i}
\end{aligned}
$$

The RPL tested is:

$$
\begin{aligned}
& U\left(X_{i}\right)=\beta_{A S C} \times A S C_{i} \\
& +\left[b_{\text {Environment }} \times \text { Environment }_{i}+b_{\text {Recreation }} \times \text { Recreation }_{i}\right. \\
& \left.+b_{\text {Health }} \times \text { Health }_{i}+b_{\text {Time }} \times \text { Time }_{i}\right] \\
& +\left[\delta_{\text {Environment, } n} \times \text { Environment }_{i}+\delta_{\text {Recreation, }, n} \times \text { Recreation }_{i}\right. \\
& \left.+\delta_{\text {Health }, n} \times \text { Health }_{i}+\delta_{\text {Time }, n} \times \text { Time }_{i}\right]+\beta_{\text {Fee }} \times \mathrm{Fee}_{i}
\end{aligned}
$$

We estimated MNL (Equation (8)) by using Stata 14's asclogit command and estimated RPL (Equation (9)) by using Stata $14^{\prime}$ s mixlogit command.

\section{Results}

The questionnaires were administered from March to November 2014 at Shei-Pa National Park. A total of 692 individuals were interviewed, of whom 81 declined the interview (8.54\%). In the end, 611 questionnaires were recovered, of which nine were invalid and 602 were valid. The valid questionnaire rate was $98.5 \%$. Each respondent was required to answer five selection sets (scenarios). However, certain respondents did not complete all the scenarios, thus reducing the number of analyzable scenarios to 2998. Table A3 presents descriptive statistics of the sample.

We used the log-likelihood ratio statistic to compare the two models [74]. From the model estimation results presented in Tables A4 and A5, the log-likelihood at convergence for the RPL model was -4430.499 with 11 parameters, compared to -5034.084 for the MNL model with 6 parameters. Therefore, the log-likelihood ratio statistic was $2(-4430.499-(-5034.084))=1207.17$ with 5 degrees of freedom, which was larger than the chi-square critical value of 20.515 at the $0.1 \%$ significance level, showing that the RPL model was statistically better than the standard MNL model in this case. Therefore, we only discuss the results of the RPL here.

The estimated values of all attribute parameters of the RPL were statistically significant (Table A5), which indicates that visitors believe that the externalities of IAS prevention and control measures had a significant impact on them. Based on Equation (5), the visitors' WTP can be obtained for the negative externality resulting from the prevention and control of IAS (Table A6). For visitors, the highest impact parameter of prevention and control measures was "Environment", followed by "Health", "Time", "Recreation", and "Fee". The utility value of "ASC" was -6.421 , which indicates that visitors believe that the utility of taking no measures to prevent or control IAS is lower than that of prevention and control.

"Environment" refers to the varying effect of different types of IAS prevention and control measures on recreational area eco-environments. The estimated value of ecological disturbance was -0.018 , which indicates that the environment of this externality will reduce visitor utility. That is, when the ecological disturbance is reduced by $1 \%$, the welfare of visitors increases by 7.571 NTD. In other words, visitors are willing to pay 7.571 NTD to reduce the environment by $1 \%$.

The "Recreation" attribute refers to the need to close recreations and reduce visitor activity space as a result of IAS prevention and control measures. The estimated value of this externality was -0.010 , which means that a reduction in recreation results in a reduction in visitor utility. In terms of willing-to-pay price, a $1 \%$ reduction in affected Recreation due to the impact of prevention and control measures will result in an increase in visitor welfare of 4.338 NTD. 
"Health" refers to the probability that prevention and control measures will negatively impact visitor health. Its estimated value was -0.015 , which indicates that the impact of prevention and control measures on visitor health will reduce visitor utility. A $1 \%$ reduction in the health caused by prevention and control will result in an increase in visitor welfare of 6.395 NTD.

"Time" refers to the time visitors spend being inspected or waiting for inspection and the time required for IAS removal. The estimated value of this attribute was -0.015 , which indicates that waiting will reduce visitor utility. A one-minute reduction in the time caused by IAS prevention and control measures will result in an increase in visitor welfare of 6.267 NTD.

"Fee" refers to the fee collected by an NP for IAS prevention and control. The estimated value of this attribute was -0.002 , which is less than the estimated value of other attributes and indicates that visitors will not prefer other negative externalities caused by IAS prevention and control. Therefore, they are willing to pay to reduce these negative externalities.

The described results illuminate the externalities of IAS prevention and control measures, their impact on visitor utility, and the price visitors are willing to pay to avoid each externality. In addition, they suggest specific guidelines for IAS prevention and control. For example, the estimated value of "Environment" was -0.018 , while the estimated value of "Recreation" was -0.010 . These outcomes mean that visitors are willing to accept loss of park area open to visitors in exchange for reducing the environment of IAS. Specifically, visitors are willing to sacrifice up to $1.8 \%$ of the recreation available to them in exchange for a $1 \%$ reduction in environment. Therefore, if limiting recreation can facilitate a park's IAS prevention and control, adopting the method with the lighter environment will still gain support from visitors even if the recreation is reduced.

The estimate value of "Health" was -0.015, and its ratio to the estimated value of "Recreation" was 1.5. This result indicates that visitors are willing to sacrifice recreation to reduce the possibility of having their health harmed, and they are willing to reduce their recreation by up to $1.5 \%$ to reduce the health by $1 \%$. Expanding a restricted area can reduce visitor exposure to IAS prevention work and materials and avoid harm to visitors. The larger that the restricted area is, the lower the health. To visitors, this does not mean that the restricted area can be increased at will or even an entire park be closed. However, the possible health remains a significant factor. If the health can be reduced by $1 \%$, the maximum acceptable reduction of recreation is $1.5 \%$.

The absolute value of the estimated value of "Environment" was higher than the absolute value of the estimated value of "Health". This outcome indicates that visitors are more concerned regarding the environment of IAS prevention and control than regarding their health. The ratio was 1.2 to 1 . That is, visitors can accept an IAS prevention and control measure that poses a higher threat to human health but has lower environment. At most, they are willing to tolerate an increase of $1.2 \%$ in health in exchange for a $1 \%$ reduction in environment.

The estimated value of "Time" was close to that of "Health", and its ratio to other externalities of IAS prevention and control (i.e., its trade-off relationship) was similar to that of "Health". Our interpretation is also similar.

This study agrees with the conclusions of the relevant literature. That is, our research results support IAS prevention and control. Rolfe and Windle [42] assessed the amount that residents of Brisbane, Australia, were willing to pay to prevent and control invasive red fire ants. The ASC of the study was negative, which indicates that the respondents preferred the IAS prevention and control plan. The ASC estimation in that study is that same as presented here. Adams, Bwenge, Lee, Larkin and Alavalapati [40] studied the willingness of Florida residents to pay admission to state parks. The results of the study show that each visitor is willing to pay an average of $\$ 5.41$ to reduce the coverage of invasive alien plants. In addition, the estimated value of biodiversity is positive, indicating that reduction in biodiversity caused by controlling IAS will affect visitor utility. This result is consistent with the negative estimate value of "Environment" in this study. The estimated value of "Recreation" in this study was negative, which indicates that a reduction in recreation caused by controlling IAS 
will reduce visitor utility. This result is consistent with the finding by Beville, et al. [75] that closing recreational fishing areas will reduce utility.

This study also presents results not found by previous researchers but that may be useful to NPs in managing IAS prevention and control. These results include visitor preferences regarding the negative externalities of IAS prevention and control measures and the willing-to-pay price to avoiding these externalities. These outcomes can help NPs determine whether their IAS prevention and control is in line with the trade-offs between the negative externalities. In this manner, NPs can adopt prevention and control measures that maximize visitor welfare. The results are concrete and suit the needs of NPs in the actual planning of IAS prevention and control, while considering the utility of NP visitors.

\section{Conclusions}

The study results show that visitors prefer to prevent and control IAS rather than do nothing. Visitors award first priority to the impact of IAS prevention and control measures on the eco-environment, followed by individual health, time, and finally reduction of recreation. Whether visitors support IAS prevention and control measures can be observed directly from ASC estimation results. A negative ASC means that the utility of choosing "none of the above" is lower than that of choosing prevention and control. Therefore, visitors prefer to prevent and control IAS. In terms of the visitors' response to the estimated results of the negative externalities of IAS prevention and control measures, visitors' marginal willing-to-pay price to reduce eco-environmental disturbance by $1 \%$ is 7.571 NTD. Their willing-to-pay price for the $1 \%$ reduction in health is 6.395 NTD. Their willing-to-pay price for a one-minute reduction in time is $6.267 \mathrm{NTD}$, and their willing-to-pay price for a $1 \%$ reduction in restricted recreation is 4.338 NTD. Reducing any of the negative externalities of IAS prevention and control measures will improve the welfare of visitors. A prevention and control measure that is in line with the trade-off of each externality will be the one that can maximize visitor welfare.

We have found that respondents prefer a strategy to prevent and control IAS that reduces the ecological disturbance and avoids restricting sightseeing and access to recreations. These research results are consistent with those of Rolfe and Windle [42], Adams, Bwenge, Lee, Larkin and Alavalapati [40], and Beville, Kerr and Hughey [75]. This study further investigated the trade-offs between the variables and found that visitors are willing to sacrifice a $1.8 \%$ reduction in recreation in exchange for a $1 \%$ reduction in ecological disturbance. This result better suits the needs of NPs in the actual planning of IAS prevention and control than the results of previous studies.

NPs preserve important ecological and cultural landscapes and are popular visitor attractions. However, IAS seriously threaten NP operation and management, creating a unique dilemma for NPs. To solve this problem, this paper clarifies the externalities of IAS prevention and control and discusses a method of assessing the trade-offs between the public and the externalities of various IAS prevention and control measures. Based on our results, we conclude that in preventing and controlling IAS, NP management must carefully consider the externalities of the prevention and control measures to make appropriate choices. In addition, assessing the trade-offs involved in the various prevention and control measures from the viewpoint of visitors provides a basis on which NPs can choose measures with the least impact on visitors (maximum utility) and that will receive the most support from them.

Funding: This work was supported by the Ministry of Science and Technology, Taiwan, under Grant NSC 101-2621-M-002-032, NSC 102-2621-M-002-027, Most 103-2621-M-002-019, and MOST 108-2410-H-110-054 -SSS programs.

Acknowledgments: The author would like to thank Chia-Mei Tien for being a research assistant in the research project. Tien helped the research group to conduct surveys in Shei-Pa National Park, as well as record the data. Information drawn from the research projects was used in Tien's thesis and Liu and Tien [69].

Conflicts of Interest: The author declares that they have no conflicts of interest. 


\section{Appendix A}

Table A1. Attributes and attribute levels.

\begin{tabular}{cccccc}
\hline Attributes & Level 1 & Level 2 & Level 3 & Level 4 & Level 5 \\
\hline Ecological impact (\%) & 0 & 15 & 30 & 45 & 60 \\
Recreational area (\%) & 0 & 20 & 40 & 60 & 80 \\
Health risks (\%) & 0 & 30 & 60 & 90 & \\
Waiting time (min) & 0 & 20 & 40 & 60 & - \\
Charges for prevention and Control (NTD) & 40 & 80 & 120 & 160 & 200 \\
\hline
\end{tabular}

Table A2. An example of ASC choice set.

\begin{tabular}{|c|c|c|c|c|c|c|}
\hline & Alternative 1 & Alternative 2 & Alternative 3 & Alternative 4 & Alternative 5 & \\
\hline $\begin{array}{l}\text { Severe disturbance to } \\
\text { the eco-environment } \\
\text { by the prevention and } \\
\text { control measures }\end{array}$ & $45 \%$ & $30 \%$ & $0 \%$ & $60 \%$ & $0 \%$ & \\
\hline $\begin{array}{c}\text { Reduction in } \\
\text { recreational or } \\
\text { visiting areas due to } \\
\text { the prevention and } \\
\text { control measures }\end{array}$ & $0 \%$ & $60 \%$ & $20 \%$ & $0 \%$ & $60 \%$ & $\begin{array}{c}\text { None of } \\
\text { these }\end{array}$ \\
\hline $\begin{array}{l}\text { Possible negative } \\
\text { impact of the } \\
\text { prevention and } \\
\text { control measures on } \\
\text { tourist health }\end{array}$ & $0 \%$ & $60 \%$ & $60 \%$ & $60 \%$ & $30 \%$ & \\
\hline $\begin{array}{c}\text { Increased tourist } \\
\text { waiting time caused } \\
\text { by implementation of } \\
\text { prevention and } \\
\text { control measures }\end{array}$ & 0 minute & 0 minute & 60 minutes & 40 minutes & 0 minute & \\
\hline $\begin{array}{l}\text { Additional fees } \\
\text { dedicated to } \\
\text { prevention and } \\
\text { control charged for } \\
\text { entering attractions or } \\
\text { parks }\end{array}$ & $\begin{array}{c}80 \\
\text { NTD }\end{array}$ & $\begin{array}{c}120 \\
\text { NTD }\end{array}$ & $\begin{array}{c}80 \\
\text { NTD }\end{array}$ & $\begin{array}{c}160 \\
\text { NTD }\end{array}$ & $\begin{array}{c}160 \\
\text { NTD }\end{array}$ & \\
\hline $\begin{array}{l}\text { Which alternative } \\
\text { would you choose? } \\
\text { (Please select and } \\
\text { mark only one } \\
\text { alternative) }\end{array}$ & $\square$ & $\square$ & $\square$ & $\square$ & $\square$ & $\square$ \\
\hline
\end{tabular}


Table A3. Descriptive statistics.

\begin{tabular}{ccc}
\hline & Sample (\%) & Taiwan Population (\%) \\
\hline Age group (in \%) & 14.0 & \\
20 and younger & 22.4 & 20.0 \\
$21-30$ & 24.9 & 13.6 \\
$31-40$ & 24.8 & 16.7 \\
$41-50$ & 8.0 & 15.4 \\
$51-60$ & 3.5 & 15.4 \\
$61-70$ & 0.5 & 10.6 \\
71 and older & & 8.3 \\
Gender (in \%) & 48.0 & \\
Male & 51.0 & 49.9 \\
Female & & 50.1 \\
\hline Education (in \%) & 1.0 & \\
Primary School & 4.7 & 12.2 \\
Junior High School & 18.9 & 12.5 \\
Senior High School & 53.7 & 30.9 \\
University & 20.4 & 36.3 \\
Graduate School & & 6.4 \\
\hline
\end{tabular}

Table A4. Results: MNL model estimates.

\begin{tabular}{ccc}
\hline Attributes & Coeff. & Std. Error \\
\hline ASC & $-1.872^{* * *}$ & 0.0846 \\
Environment & $-0.014^{* * *}$ & 0.0011 \\
Recreation & $-0.010^{* * *}$ & 0.0008 \\
Health & $-0.011^{* * *}$ & 0.0007 \\
Time & $-0.011^{* *}$ & 0.0010 \\
Fee & $-0.002^{*}$ & 0.0004 \\
\hline Observations & 2998 & \\
Respondents & 602 & \\
Log-likelihood & -5034.084 & \\
\hline
\end{tabular}

Note: $1 .{ }^{*} p<0.05^{* *} p<0.025^{* * *} p<0.01 ; 2$. Calculations based on parameter estimates of Equation (5); 3. ASC, alternative specific constant.

Table A5. Results: RPL model estimates.

\begin{tabular}{ccc}
\hline Variables & Coeff. & Std. Error \\
\hline & Random parameter means & \\
\hline ASC $_{-}^{\text {a }}$ & $-6.421^{* * *}$ & 0.516 \\
Environment $^{* * *}$ & 0.002 \\
Recreation $^{*}-0.018^{* * *}$ & 0.001 \\
Health & $-0.010^{* * *}$ & 0.001 \\
Time & $-0.015^{* * *}$ & 0.001 \\
\hline & $-0.015^{* * *}$ & \\
\hline Fee & Non-random parameter means & 0.000 \\
\hline & $-0.002^{* * *}$ & \\
\hline ASC ${ }_{-}^{\text {a }}$ & Random parameter standard deviations \\
Environment & $5.278^{* * *}$ & 0.488 \\
Recreation & $0.027^{* * *}$ & 0.002 \\
Health & $0.0053^{* *}$ & 0.0027 \\
Time & $0.023^{* * *}$ & 0.002 \\
& $0.013^{* * *}$ & 0.002 \\
\hline
\end{tabular}


Table A5. Results: RPL model estimates.

\begin{tabular}{ccc}
\hline Variables & Coeff. & Std. Error \\
\hline Summary statistics & \\
Observations & 2998 \\
Respondents & 602 \\
Log likelihood & -4430.499 \\
\hline Note: ${ }^{*} p<0.05^{* *} p<0.025^{* * *} p<0.01_{-}^{\text {a }}$ ASC, alternative specific constant.
\end{tabular}

Table A6. WTP estimates.

\begin{tabular}{cccc}
\hline Attribute & MNL & \multicolumn{2}{c}{ RPL } \\
\hline & & Mean & 95\% Conf. Int. \\
\hline ASC & -1248.8 & -2754.321 & $(-4507.754,-1928.333)$ \\
Environment & -9.3 & -7.571 & $(-12.962,-5.042)$ \\
Recreation & -6.6 & -4.338 & $(-7.416,-2.888)$ \\
Health & -7.3 & -6.395 & $(-10.702,-4.381)$ \\
Time & -7.1 & -6.267 & $(-10.939,-4.126)$ \\
\hline
\end{tabular}

\section{References}

1. Pimentel, D.; Lach, L.; Zuniga, R.; Morrison, D. Environmental and Economic Costs of Nonindigenous Species in the United States. BioScience 2000, 50, 53-65. [CrossRef]

2. Lodge, D.M.; Simonin, P.W.; Burgiel, S.W.; Keller, R.P.; Bossenbroek, J.M.; Jerde, C.L.; Kramer, A.M.; Rutherford, E.S.; Barnes, M.A.; Wittmann, M.E. Risk analysis and bioeconomics of invasive species to inform policy and management. Annu. Rev. Environ. Resour. 2016, 41, 453-488. [CrossRef]

3. Sharp, R.L.; Larson, L.R.; Green, G.T. Factors influencing public preferences for invasive alien species management. Biol. Conserv. 2011, 144, 2097-2104. [CrossRef]

4. Hario, M. The Archipelago Birds Census in 1999: Recent trends of common eider, alcids and sea terns in Finland. Yearb. Linnut Mag. 2000, 1999, 40-50.

5. Nordström, M.; Högmander, J.; Nummelin, J.; Laine, J.; Laanetu, N.; Korpimäki, E. Variable responses of waterfowl breeding populations to long-term removal of introduced American mink. Ecography 2002, 25, 385-394. [CrossRef]

6. Beever, E.A.; Huso, M.; Pyke, D.A. Multiscale responses of soil stability and invasive plants to removal of non-native grazers from an arid conservation reserve. Divers. Distrib. 2006, 12, 258-268. [CrossRef]

7. Gutiérrez-Yurrita, P.J.; Montes, C. Bioenergetics and phenology of reproduction of the introduced red swamp crayfish, Procambarus clarkii, in Do-ana National Park, Spain, and implications for species management. Freshw. Biol. 1999, 42, 561-574. [CrossRef]

8. Lejju, J. Ecological recovery of an afromontane forest in south-western Uganda. Afr. J. Ecol. 2004, 42, 64-69. [CrossRef]

9. Streelman, J.T.; Gmyrek, S.; Kidd, M.; Kidd, C.; Robinson, R.; Hert, E.; Ambali, A.; Kocher, T. Hybridization and contemporary evolution in an introduced cichlid fish from Lake Malawi National Park. Mol. Ecol. 2004, 13, 2471-2479. [CrossRef]

10. Magara, Y.; Matsui, Y.; Goto, Y.; Yuasa, A. Invasion of the non-indigenous nuisance mussel, Limnoperna fortunei, into water supply facilities in Japan. J. Water Supply: Res. Technol. Aqua 2001, 50, 113-124. [CrossRef]

11. Darrigran, G.; Damborenea, C. A South American bioinvasion case history: Limnoperna fortunei (Dunker, 1857), the golden mussel. Am. Malacol. Bull. 2005, 20, 105-112.

12. Malik, A. Environmental challenge vis a vis opportunity: The case of water hyacinth. Environ. Int. 2007, 33, 122-138. [CrossRef] [PubMed]

13. Burnett, K.M.; D'evelyn, S.; Kaiser, B.A.; Nantamanasikarn, P.; Roumasset, J.A. Beyond the lamppost: Optimal prevention and control of the brown tree snake in Hawaii. Ecol. Econ. 2008, 67, 66-74. [CrossRef] 
14. Julia, R.; Holland, D.W.; Guenthner, J. Assessing the economic impact of invasive species: The case of yellow starthistle (Centaurea solsitialis L.) in the rangelands of Idaho, USA. J. Environ. Manag. 2007, 85, 876-882. [CrossRef] [PubMed]

15. Belmonte, J.; Vilà, M. Atmospheric invasion of non-native pollen in the Mediterranean region. Am. J. Bot. 2004, 91, 1243-1250. [CrossRef] [PubMed]

16. Pyšek, P.; Cock, M.; Nentwig, W.; Ravn, H. Ecology and Management of Giant Hogweed (Heracleum mantegazzianum). CAB International; Cabi Publishing: Oxfordshire, UK, 2007.

17. Jayaramiah, R.; Krishnaprasad, B.; Kumar, S.; Pramodh, G.; Ramkumar, C.; Sheshadri, T. Harmful effects of Parthenium hysterophorus and management through different approaches-A review. Ann. Plant Sci. 2017, 6, 1614-1621.

18. Wylie, F.R.; Janssen-May, S. Red Imported Fire Ant in Australia: What if we lose the war? Ecol. Manag. Restor. 2017, 18, 32-44. [CrossRef]

19. Gutrich, J.J.; VanGelder, E.; Loope, L. Potential economic impact of introduction and spread of the red imported fire ant, Solenopsis invicta, in Hawaii. Environ. Sci. Policy 2007, 10, 685-696. [CrossRef]

20. Rhoades, R.B.; Stafford, C.T.; James, F.K. Survey of fatal anaphylactic reactions to imported fire ant stings. J. Allergy Clin. Immunol. 1989, 84, 159-162. [CrossRef]

21. Bradshaw, C.J.; Leroy, B.; Bellard, C.; Roiz, D.; Albert, C.; Fournier, A.; Barbet-Massin, M.; Salles, J.-M.; Simard, F.; Courchamp, F. Massive yet grossly underestimated global costs of invasive insects. Nat. Commun. 2016, 7, 12986. [CrossRef]

22. Paini, D.R.; Sheppard, A.W.; Cook, D.C.; De Barro, P.J.; Worner, S.P.; Thomas, M.B. Global threat to agriculture from invasive species. Proc. Natl. Acad. Sci. USA 2016, 113, 7575-7579. [CrossRef] [PubMed]

23. Booy, O.; Cornwell, L.; Parrott, D.; Sutton-Croft, M.; Williams, F. Impact of biological invasions on infrastructure. In Impact of Biological Invasions on Ecosystem Services; Springer: Cham, Switzerland, 2017; pp. 235-247.

24. Chen, J. Toxicity and efficacy of two Emulsifiable concentrates of 2-Tridecanone against red imported fire Ants. Adv. Entomol. 2015, 4, 37-46. [CrossRef]

25. Douglas, M.R.; Tooker, J.F. Large-scale deployment of seed treatments has driven rapid increase in use of neonicotinoid insecticides and preemptive pest management in US field crops. Environ. Sci. Technol. 2015, 49, 5088-5097. [CrossRef] [PubMed]

26. Allison, J.D.; Redak, R.A. The impact of trap type and design features on survey and detection of bark and woodboring beetles and their associates: A review and meta-analysis. Annu. Rev. Entomol. 2017, 62, 127-146. [CrossRef]

27. Juanes, F. Visual and acoustic sensors for early detection of biological invasions: Current uses and future potential. J. Nat. Conserv. 2018, 42, 7-11. [CrossRef]

28. Gomes, J.; Matos, A.; Quinta-Ferreira, R.M.; Martins, R.C. Environmentally applications of invasive bivalves for water and wastewater decontamination. Sci. Total Environ. 2018, 630, 1016-1027. [CrossRef]

29. Colleran, B.P.; Goodall, K.E. In situ growth and rapid response management of flood-dispersed Japanese knotweed (Fallopia japonica). Invasive Plant Sci. Manag. 2014, 7, 84-92. [CrossRef]

30. Stark, J.D.; Chen, X.D.; Johnson, C.S. Effects of herbicides on Behr's metalmark butterfly, a surrogate species for the endangered butterfly, Lange's metalmark. Environ. Pollut. 2012, 164, 24-27. [CrossRef]

31. Koureas, M.; Tsakalof, A.; Tsatsakis, A.; Hadjichristodoulou, C. Systematic review of biomonitoring studies to determine the association between exposure to organophosphorus and pyrethroid insecticides and human health outcomes. Toxicol. Lett. 2012, 210, 155-168. [CrossRef]

32. Ip, K.K.; Liang, Y.; Lin, L.; Wu, H.; Xue, J.; Qiu, J.-W. Biological control of invasive apple snails by two species of carp: Effects on non-target species matter. Biol. Control 2014, 71, 16-22. [CrossRef]

33. Olivier-Espejel, S.; Hurley, B.P.; Garnas, J. Assessment of beetle diversity, community composition and potential threats to forestry using kairomone-baited traps. Bull. Entomol. Res. 2017, 107, 106-117. [CrossRef] [PubMed]

34. LeDoux, C.B.; Martin, D.K. Proposed BMPs for Invasive Plant Mitigation during Timber Harvesting Operations; USDA Forest Service: Newtown Square, PA, USA, 2013.

35. Judge, C.A.; Neal, J.C.; Shear, T.H. Japanese stiltgrass (Microstegium vimineum) management for restoration of native plant communities. Invasive Plant Sci. Manag. 2008, 1, 111-119. [CrossRef]

36. Buckley, Y.M.; Han, Y. Managing the side effects of invasion control. Science 2014, 344, 975-976. [CrossRef] 
37. Head, L.; Larson, B.M.; Hobbs, R.; Atchison, J.; Gill, N.; Kull, C.; Rangan, H. Living with invasive plants in the Anthropocene: The importance of understanding practice and experience. Conserv. Soc. 2015, 13, 311.

38. Nimmo, D.G.; Miller, K.K. Ecological and human dimensions of management of feral horses in Australia: A review. Wildl. Res. 2007, 34, 408-417. [CrossRef]

39. Mwebaze, P.; MacLeod, A.; Tomlinson, D.; Barois, H.; Rijpma, J. Economic valuation of the influence of invasive alien species on the economy of the Seychelles islands. Ecol. Econ. 2010, 69, 2614-2623. [CrossRef]

40. Adams, D.C.; Bwenge, A.N.; Lee, D.J.; Larkin, S.L.; Alavalapati, J.R. Public preferences for controlling upland invasive plants in state parks: Application of a choice model. For. Policy Econ. 2011, 13, 465-472. [CrossRef]

41. McIntosh, C.R.; Shogren, J.F.; Finnoff, D.C. Invasive species and delaying the inevitable: Valuation evidence from a national survey. Ecol. Econ. 2010, 69, 632-640. [CrossRef]

42. Rolfe, J.; Windle, J. Public preferences for controlling an invasive species in public and private spaces. Land Use Policy 2014, 41, 1-10. [CrossRef]

43. Bithas, K.; Latinopoulos, D.; Kolimenakis, A.; Richardson, C. Social benefits from controlling invasive Asian tiger and native mosquitoes: A stated preference study in Athens, Greece. Ecol. Econ. 2018, 145, 46-56. [CrossRef]

44. Chakir, R.; David, M.; Gozlan, E.; Sangare, A. Valuing the impacts of an invasive biological control agent: A choice experiment on the Asian ladybird in France. J. Agric. Econ. 2016, 67, 619-638. [CrossRef]

45. Boxall, P.C.; Adamowicz, W.L.; Swait, J.; Williams, M.; Louviere, J. A comparison of stated preference methods for environmental valuation. Ecol. Econ. 1996, 18, 243-253. [CrossRef]

46. Kanninen, B.J. Valuing environmental amenities using stated choice studies: A common sense approach to theory and practice; Springer: Dordrecht, The Netherlands, 2007; Volume 8.

47. Kjær, T. A review of the discrete choice experiment-with emphasis on its application in health care; Syddansk Universitet Denmark: Odense, Denmark, 2005.

48. Lee, C.E. Evolutionary genetics of invasive species. Trends Ecol. Evol. 2002, 17, 386-391. [CrossRef]

49. Thomas, M.B.; Reid, A.M. Are exotic natural enemies an effective way of controlling invasive plants? Trends Ecol. Evol. 2007, 22, 447-453. [CrossRef]

50. Brown, M.; Roth, J.; Smith, B.; Boscarino, B. The light at the end of the funnel?: Using light-based traps for the detection and collection of a nearshore aquatic, invasive invertebrate, Hemimysis anomala. J. Great Lakes Res. 2017, 43, 717-727. [CrossRef]

51. Haack, R.A.; Britton, K.O.; Brockerhoff, E.G.; Cavey, J.F.; Garrett, L.J.; Kimberley, M.; Lowenstein, F.; Nuding, A.; Olson, L.J.; Turner, J. Effectiveness of the International Phytosanitary Standard ISPM No. 15 on reducing wood borer infestation rates in wood packaging material entering the United States. PLoS One 2014, 9, e96611. [CrossRef]

52. Tobin, P.C.; Liebhold, A.M.; Anderson Roberts, E. Comparison of methods for estimating the spread of a non-indigenous species. J. Biogeogr. 2007, 34, 305-312. [CrossRef]

53. Bothwell, M.L.; Lynch, D.R.; Wright, H.; Deniseger, J. On the boots of fishermen: The history of Didymo blooms on Vancouver Island, British Columbia. Fisheries 2009, 34, 382-388. [CrossRef]

54. Corona, P.; Chirici, G.; McRoberts, R.E.; Winter, S.; Barbati, A. Contribution of large-scale forest inventories to biodiversity assessment and monitoring. For. Ecol. Manag. 2011, 262, 2061-2069. [CrossRef]

55. Lindenmayer, D.B.; Wood, J.H.; Christopher Macgregor, R.J.H.; Catford, J.A. Non-target impacts of weed control on birds, mammals and reptiles. Ecosphere 2017, 8, e01804.

56. Ryan, M.; Gerard, K.; Amaya-Amaya, M. Using discrete choice experiments to value health and health care; Springer: Dordrecht, The Netherlands, 2007; Volume 11.

57. Gundersen, V.; Mehmetoglu, M.; Vistad, O.I.; Andersen, O. Linking visitor motivation with attitude towards management restrictions on use in a national park. J. Outdoor Recreat. Tour. 2015, 9, 77-86. [CrossRef]

58. Zhang, H.; Zhang, J.; Kuwano, M. An integrated model of tourists' time use and expenditure behaviour with self-selection based on a fully nested Archimedean copula function. Tour. Manag. 2012, 33, 1562-1573. [CrossRef]

59. Rose, J.; Bliemer, M.C. Stated choice experimental design theory: The who, the what and the why. In Handbook of Choice Modelling; Hess, S., Daly, A., Eds.; Edward Elgar Publishing: Glos, UK, 2014; pp. 152-177.

60. Johnson, F.R.; Kanninen, B.; Bingham, M.; Özdemir, S. Experimental design for stated-choice studies. In Valuing Environmental Amenities Using Stated Choice Studies; Springer: Dordrecht, The Netherlands, 2006; pp. 159-202. 
61. Rischatsch, M. Who joins the network? Physicians' resistance to take budgetary co-responsibility. J. Health Econ. 2015, 40, 109-121. [CrossRef] [PubMed]

62. Kessels, R. Homogeneous versus heterogeneous designs for stated choice experiments: Ain't homogeneous designs all bad? J. Choice Model. 2016, 21, 2-9. [CrossRef]

63. Hanley, N.; Mourato, S.; Wright, R.E. Choice modelling approaches: A superior alternative for environmental valuatioin? J. Econ. Surv. 2001, 15, 435-462. [CrossRef]

64. Liu, T.-M. Testing on-site sampling correction in discrete choice experiments. Tour. Manag. 2017, 60, 439-441. [CrossRef]

65. McFadden, D. Econometric Models of Probabilistic Choice; The MIT Press: London, UK, 1981.

66. Hoyos, D. The state of the art of environmental valuation with discrete choice experiments. Ecol. Econ. 2010, 69, 1595-1603. [CrossRef]

67. Tempesta, T.; Vecchiato, D.; Girardi, P. The landscape benefits of the burial of high voltage power lines: A study in rural areas of Italy. Landsc. Urban Plan. 2014, 126, 53-64. [CrossRef]

68. Train, K.E. Discrete Choice Methods with Simulation; Cambridge University Press: New York, NY, USA, 2009.

69. Liu, T.-M.; Tien, C.-M. Assessing Tourists' Preferences of Negative Externalities of Environmental Management Programs: A Case Study on Invasive Species in Shei-Pa National Park, Taiwan. Sustainability 2019, 11, 2953. [CrossRef]

70. Prosser, L.A.; Payne, K.; Rusinak, D.; Shi, P.; Uyeki, T.; Messonnier, M. Valuing health across the lifespan: Health state preferences for seasonal influenza illnesses in patients of different ages. Value Health 2011, 14, 135-143. [CrossRef]

71. Bolhaar, J.; Lindeboom, M.; Van Der Klaauw, B. A dynamic analysis of the demand for health insurance and health care. Eur. Econ. Rev. 2012, 56, 669-690. [CrossRef]

72. Croson, R.; Gneezy, U. Gender differences in preferences. J. Econ. Lit. 2009, 47, 448-474. [CrossRef]

73. Train, K.E. Recreation demand models with taste differences over people. Land economics 1998, $230-239$. [CrossRef]

74. Hensher, D.A.; Rose, J.M.; Greene, W.H. Applied Choice Analysis: A Primer; Cambridge University Press: New York, NY, USA, 2005.

75. Beville, S.T.; Kerr, G.N.; Hughey, K.F. Valuing impacts of the invasive alga Didymosphenia geminata on recreational angling. Ecol. Econ. 2012, 82,1-10. [CrossRef]

(C) 2019 by the author. Licensee MDPI, Basel, Switzerland. This article is an open access article distributed under the terms and conditions of the Creative Commons Attribution (CC BY) license (http://creativecommons.org/licenses/by/4.0/). 